\title{
Analysis of Mechanical Behavior and Microstructural Characteristics Change of ASTM A-36 Steel Applying Various Heat Treatment
}

Hasan MF*

Department of Industrial Engineering and Management, Khulna University of Engineering and Technology, Khulna-9203, Bangladesh

\begin{abstract}
In this study ASTM A-36 (mild steel) is selected as specimen for testing various mechanical properties and microstructure change. The effects of heat treatment on the mechanical properties and microstructure characteristics change of selected specimen are analyzed. Annealing, hardening and tempering are the most important heat treatment processes often used to change mechanical properties of engineering materials. The purpose of heat treating is to analyze the mechanical properties of the steel, usually ductility, hardness, Yield strength, tensile strength and impact resistance. The heat treatment develops hardness, softness, and improves the mechanical properties such as tensile strength, yield strength, ductility, corrosion resistance and creep rupture. These processes also help to improve machining effect, and make them versatile. The mechanical properties can easily be modified by heat treating to suit a particular design purpose. In the present study, selected samples are heat-treated at certain temperature above the austenitic region and quenched in order to investigate the effect on the mechanical properties microstructure of the mild steel. The changes in mechanical behavior and microstructure as compared with unquenched samples are explained in terms of changes in tensile strength. Results showed that the mechanical properties of mild steel can be changed and improved by various heat treatments for a particular application.
\end{abstract}

Keywords: Heat treatment; Mild steel; Mechanical properties; Microstructure; Universal testing machine; Rockwell hardness tester

\section{Introduction}

The subject of mechanical testing of materials is an important aspect of engineering practice. Today, more concern is being given to the interpretation of test results in terms of service performance, as well as giving reliable indications of the ability of the material to perform certain types of duty. Mechanical tests are also employed in investigational work in order to obtain data for use in design to ascertain whether the material meets the specifications for its intended use. Heat treatment is defined as an operation or combination of operations involving heating and cooling of a metal or alloy for this case involving the mild steel in the solid state in such ways as to produce certain microstructure and desired mechanical properties (hardness, toughness, yield strength, ultimate tensile strength, Young's modulus, percentage elongation and percentage reduction). Annealing, normalizing, hardening and tempering are the most important heat treatments often used to modify the microstructure and mechanical properties of engineering materials particularly steels. Annealing is defined as a heat treatment that consists of heating to and holding at a suitable temperature followed by cooling at an appropriate rate, most frequently applied in order to soften iron or steel materials and refines its grains due to ferrite-pearlite microstructure; it is used where elongations and appreciable level of tensile strength are required in engineering materials. Hardening is the heat treatment processes in which increases the hardness of a steel piece by heating it to a certain temperature and then cooling it rapidly to room temperature. Tempering is the process of imparting toughness at the cost of its hardness to an already hardened piece of steel by reheating it to a certain temperature and then cooling it rapidly. The temperature of heating depends on the toughness to be imparted and hardness to be reduced. In normalizing, the material is heated to the austenitic temperature range and this is followed by air cooling. This treatment is usually carried out to obtain a mainly pearlite matrix, which results into strength and hardness higher than in as received condition. It is also used to remove undesirable free carbide present in the as-received sample [1].
Steel is an alloy of iron with definite percentage of carbon ranges from $0.15-1.5 \%$ [2], plain carbon steels are those containing $0.1-0.25 \%$ [3]. Steel is mainly an alloy of iron and carbon, where other elements are present in quantities too small to affect the properties. The other alloying elements allowed in plain-carbon steel are manganese and silicon. Steel with low carbon content has the same properties as iron, soft but easily formed. As carbon content rises, the metal becomes harder and stronger but less ductile and more difficult to weld. There are two main reasons for the popular use of steel: (1) It is abundant in the earth's crust in form of $\mathrm{Fe}_{2} \mathrm{O}_{3}$ and little energy is required to convert it to $\mathrm{Fe}$. (2) It can be made to exhibit great variety of microstructures and thus a wide range of mechanical properties. Although the number of steel specifications runs into thousands, plain carbon steel accounts for more than $90 \%$ of the total steel output. The reason for its importance is that it is a tough, ductile and cheap material with reasonable casting, working and machining properties, which is also amenable to simple heat treatments to produce a wide range of properties [1]. The purpose of heat treating carbon steel is to change the mechanical properties of steel, usually ductility, hardness, Yield strength, tensile strength and impact resistance. The standard strengths of steels used in the structural design are prescribed from their yield strength. Most engineering calculations for structure are based on yield strength. The heat treatment develops hardness, softness, and improves the mechanical properties (such as tensile strength, yield strength, ductility, corrosion resistance and creep rupture. These processes

*Corresponding author: Hasan MF, Department of Industrial Engineering and Management, Khulna University of Engineering and Technology, Khulna-9203, Bangladesh, Tel: 8801611555554; E-mail: ferdaus2k11@gmail.com

Received May 09, 2015; Accepted January 21, 2016; Published January 31 2016

Citation: Hasan MF (2016) Analysis of Mechanical Behavior and Microstructural Characteristics Change of ASTM A-36 Steel Applying Various Heat Treatment. J Material Sci Eng 5: 227. doi:10.4172/2169-0022.1000227

Copyright: @ 2016 Hasan MF. This is an open-access article distributed under the terms of the Creative Commons Attribution License, which permits unrestricted use, distribution, and reproduction in any medium, provided the original author and source are credited. 
also help to improve machining effect, and make them versatile. They are found in applications such as train railroads, beams for building support structures, reinforcing rods in concrete, ship construction, tubes for boilers in power generating plants, oil and gas pipelines, car radiators, cutting tools etc. [3]. The mild steel or called low carbon steel as the main component to through the process of the heat treatment where it containing several characteristic. The general range of mild steel is $0.05 \%$ to $0.35 \%$. Mild steel is a very versatile and useful material. It can be machined and worked into complex shapes has low cost and good mechanical properties. It is forms the vast bulk of the steels employed for general structural fabrication, sheet metal and so on. Bolts and studs are supposed to be made from mild steel (up to $0.25 \%$ carbon) with characteristic toughness and ductility.

\section{Various Microstructures}

Prediction of microstructure transformations is prerequisite for successful prediction of mechanical properties after a heat treatment and of generation of stresses and strains during a heat treatment. Phase transformation modeling is one of the main challenges in modeling of heat treatment [4]. During annealing, softening processes are under way in the microstructure and, in some cases, recovery and recrystallization take place as well. Naturally, the morphology of carbides changes as well [5].

\section{Ferrite}

It is a-iron (B.C.C.) having not more than $0.025 \%$ carbon in solid solution. It is major constituent in low carbon steels and wrought iron. Its hardness varies from 50 to 100 B.H.N. Its upper tensile strength is about $330 \mathrm{MN} / \mathrm{m}^{2}$ and percentage elongation about 40 . It can be easily cold worked [6].

\section{Cementite}

It is iron carbide, with $6.67 \%$ carbon. Its upper tensile strength is about $45 \mathrm{MN} / \mathrm{m}^{2}$ and hardness about 650 B.H.N. It is white in color and is brittle. It occurs in steels which have been cooled slowly. It is magnetic below $250^{\circ} \mathrm{C}$. In steels containing carbon less than $0.8 \%$ it is present as a component of another constituent, "pearlite". In steels containing more than $0.8 \%$ carbon it exists as a grain boundary film [6].

\section{Pearlite}

In its microstructure it consists of alternate laminations of ferrite and cementite. It contains about $0.8 \%$ carbon in iron. It is the strongest constituent of steel. Its hardness is about 180 B.H.N., ultimate tensile strength about $920 \mathrm{MN} / \mathrm{m}^{2}$ and percentage elongation about 5\% [6].

\section{Austenite}

It is a solid solution of carbon in ý-iron (F.C.C.) containing a maximum of $2 \%$ carbon at $1130^{\circ} \mathrm{C}$. It is tough and non-magnetic. It exists in plain carbon steels above upper critical temperature. Elements like chromium and manganese in steel preserve all or some of austenite down to $0^{\circ} \mathrm{C}$. Austenite consists of polyhedral grains showing twins [6].

\section{Martensite}

In plain carbon steel it is obtained by quenching from above upper critical temperature. It is the hardest constituent obtained in given steel. It shows a fine needle-like microstructure. Its hardness is about 700 B.H.N. It is unstable and disappears on reheating the steel. It is magnetic and less tough than austenite. It is considered to be highly stressed $\alpha$-iron supersaturated with carbon [6].

\section{Materials and Methods}

Sample of ASTM A-36 mild steel was purchased from a local market located in Khulna, Bangladesh. All specimens of mild steel of dimensions $8 \times 8 \times 8 \mathrm{~mm}$ was cut using power hacksaw. The chemical composition of the mild steel sample was determined as given in Table 1. Standard tensile and impact specimens were made from ASTM A-36 mild steel sample using lathe machine. Samples were subjected to different heat treatment: annealing, normalizing, hardening, and tempering in accordance to ASM International Standards [7]. Heat treated specimens were tested for mechanical properties. The heat treatment conditions are listed in Table 2. Four specimens were prepared for each heat treatment type.

\section{Material composition}

The chemical composition of ASTM A-36 steel shown in Table 1.

\section{Working steps}

The following steps were carried out in our experimental investigation:

I. Samples of ASTM A36 steel were prepared for mechanical properties test.

II. After that the following specimens were heat treated in the furnace for reaching the austenization temperature $\left(850-900^{\circ} \mathrm{C}\right)$ of the following specimens.

III. Then the specific heat treatment operation like hardening, annealing and normalizing had been done.

IV. For specific heat treated specimen, the change of mechanical properties was determined in the following (2.1) using appropriate methods.

V. Metallographic tests were carried out to observe the changes in microstructures after heat treatment.

For annealing: In this case the specimen was put in the furnace for $910^{\circ} \mathrm{C}$ and we kept it in this situation for approximately 70 minutes. After that it was cooled in a heap of ashes so that it was cooled down at a very slow rate.

For hardening: In this case the specimen was put in the furnace for $910^{\circ} \mathrm{C}$ and we kept it in this situation for approximately 30 minutes. After that it was cooled in water so that it was cooled down very quickly.

For normalizing: In this case the specimen was put in the furnace for $910^{\circ} \mathrm{C}$ and we kept it in this situation for approximately 70 minutes. After that it was cooled in room temperature (Air).

For tempering: In this case the specimen was put in the furnace for $450^{\circ} \mathrm{C}$ and we kept it in this situation for approximately 70 minutes. After that it was cooled in room temperature (Air).

\begin{tabular}{|c|c|c|c|c|c|c|c|}
\hline Iron family & $\mathbf{C} \%$ & $\mathbf{S i} \%$ & $\mathbf{M n} \%$ & $\mathbf{S} \%$ & $\mathbf{P} \%$ & $\mathbf{F e} \%$ & $\mathbf{C u} \%$ \\
\hline Mild steel & 0.29 & 0.28 & 0.10 & 0.10 & 0.04 & 98.14 & 0.2 \\
\hline
\end{tabular}

Table 1: Chemical composition of mild steel.

\begin{tabular}{|c|c|c|c|c|}
\hline Condition & Annealed & Normalized & Hardened & Tempered \\
\hline Temperature, ${ }^{\circ} \mathrm{C}$ & 910 & 910 & 910 & 450 \\
\hline Holding time, min & 70 & 70 & 30 & 70 \\
\hline Cooling medium & Ash & Air & Water & Air \\
\hline
\end{tabular}

Table 2: Summary of heat treatment process. 


\section{Determination of mechanical properties}

Mechanical properties (hardness, tensile strength, toughness, yield strength, elongation and percentage of elongation) of the treated and untreated samples are determined using standard methods. For hardness testing, oxide layers formed during heat treatment were removed by stage-wise grinding and then polished. Average Rockwell Hardness Number (BHN) readings were determined by taking two hardness readings at different positions on the samples, using a Standard Rockwell hardness tester and tensile test using universal testing machine. Impact energy was recorded using the Izod impact tester. For tensile properties, tensile specimens were loaded into a 2000 $\mathrm{kg}$ Mosanto Tensiometer hooked up to a data logger. Load-elongation data were recorded and converted into stress-strain graphs. Yield strength, ultimate (tensile) strength, Young's modulus and ductility (\% elongation and reduction) are determined based on these graphs, in accordance with ASTM standard test procedures (ASTM A-36) [8-10].

\section{Microstructure examination}

Microstructure examination of the treated and untreated samples was carried out. Each sample was carefully grounded progressively on emery paper in decreasing coarseness. The grinding surface of the samples were polished using $\mathrm{Al}_{2} \mathrm{O}_{3}$ carried on a micro clothe. The crystalline structure of the specimens were made visible by etching using solution containing 5\% Cupric cloride, $8 \% \mathrm{HCl}$ acid and $87 \%$ methylated spirit on the polished surfaces. Microscopic examination of the etched surface of various specimens was undertaken using a metallurgical microscope with an inbuilt camera through which the resulting microstructure of the samples were all photographically recorded with magnification of 400 [11,12].

\section{Results and Discussions}

\section{Effect of heat treatment on mechanical properties}

The effect of heat treatment (annealing, normalising, hardening, and tempering) on the mechanical properties (ultimate tensile strength, hardness, toughness, percentage elongation, and percentage reduction) of the treated and untreated samples is shown in Table 3. The function of annealing is to restore ductility and also removes internal stresses but its Brinell Hardness Number is less than hardening because here carbon get more time to react with oxygen in the atmosphere for slow cooling rate. The function of hardening is to increase the hardness of the specimen and so its Brinell hardness number is larger than annealing and normalizing because here carbon cannot get more time to react with oxygen (for quick cooling rate), so carbon is trapped with the specimen and formed martensite.

Normalizing does not soften the steel to the extent it is done by annealing and also it does not restore ductility as much as is done by annealing. Its Brinell Hardness Number is less than hardening but greater than annealing. Tempering imparts toughness at the cost of its hardness to an already hardened piece of steel by reheating it to a certain temperature and the cooling it rapidly.

The untreated samples value of mechanical behavior was noted as follows: tensile strength $402.45 \mathrm{MPa}$, yield strength $220.03 \mathrm{MPa}$, hardness $69.80 \mathrm{HRC}$, toughness J, percentage of elongation $23.16 \%$, percentage of reduction $56.24 \%$, young modulus $207.88 \mathrm{Gpa}$, yield strength $217.31 \mathrm{~N} / \mathrm{mm}^{2}$. Comparing the mechanical properties of annealed sample with the untreated sample, annealed sample showed that lower tensile strength (389.34 MPa), yield strength $212.54 \mathrm{MPa}$ and hardness (62.15 HRC) and increase in reduction in area (25.22\%), elongation (64.12\%), modulus of elasticity (302.32 GPa). The decrease in tensile strength and hardness can be associated with the formation of soft ferrite matrix in the microstructure of the annealed sample by cooling. The mechanical properties of the normalized specimen are found to be $452.13 \mathrm{MPa}, 242.26 \mathrm{MPa}, 120.36 \mathrm{HRC}, 63.23 \%$ and $22.70 \%$ for tensile strength, yield strength, hardness, percentage reduction and percentage elongation, respectively. The increase in tensile strength and hardness as compared to annealed and untreated sample was due to proper austenising temperature at $910^{\circ} \mathrm{C}$ and higher cooling rate, which resulted in decrease in elongation, which was lower than those obtained for untreated and annealed samples due to pearlite matrix structure obtained during normalization of ASTM A-36 steel.

The mechanical properties of the hardened sample revealed that it had the highest value of tensile strength $734.32 \mathrm{MPa}$, yield strength 278.11 MPa and highest hardness (293.4 HRC) were obtained. The specimen was austenite at $910^{\circ} \mathrm{C}$ for 30 minutes and then water quenched. This treatment increased the tensile strength and hardness but there was massive reduction in elongation and reduction in area $6.90 \%$, and $37.39 \%$, respectively.

The mechanical properties of tempered sample showed that the tensile strength, yield strength, hardness, percentage reduction and percentage elongation were $421.76 \mathrm{MPa}, 232.78 \mathrm{MPa}, 100.01$ HRC, $69.01 \%$ and $23.20 \%$, respectively. Comparing the mechanical properties of tempered sample with hardened sample, it was found that there was decrease in tensile strength and hardness at tempering temperature $450^{\circ} \mathrm{C}$ while the percentage elongation and percentage reduction increased which can be associated to the graphitization of the precipitated carbides that resulted in the formation of ferrite at tempering temperature of $450^{\circ} \mathrm{C}$. This showed that tempering temperature improved the degree of tempering of the martensite, softening the matrix and decreased its resistance of plastic deformation. However, the test results showed that annealing treatment gave an elongation superior to any other heat treatment studied. The variability in ultimate tensile strength, percentage elongation, percentage reduction hardness and toughness of treated and untreated ASTM A-36 steel are shown in Figures 1-5, respectively.

The value of tensile strength were observed to be in the order; hardened $>$ normalized $>$ tempered $>$ untreated $<$ annealed, possibly as a result of the refinement of the primary phase after the subsequent cooling processes. The value of hardness was observed to be higher for the hardened steel specimen. The hardness of the steel increases both with cooling rate and pearlite percentage. The reason being that martensite is one of the strengthening phases in steel. The increase in the hardness was due to the delay in the formation of pearlite and martensite at a higher cooling rate. The yield strength value for the hardened specimen was also observed to be greater than that of normalized and annealed specimens, while the normalized specimen also has a greater value than that of tempered and annealed specimen. It was also observed from the graphs that for all the heat treated

\begin{tabular}{|c|c|c|c|c|c|c|}
\hline \multicolumn{7}{|c|}{ Mechanical properties } \\
\hline $\begin{array}{c}\text { Heat } \\
\text { Treatment }\end{array}$ & $\begin{array}{c}\text { Tensile } \\
\text { Strength } \\
\text { (Mpa) }\end{array}$ & $\begin{array}{c}\text { Hardness } \\
\text { (BHN) }\end{array}$ & $\begin{array}{c}\text { Percentage } \\
\text { Elongation } \\
(\%)\end{array}$ & $\begin{array}{c}\text { Percentage } \\
\text { Reduction } \\
(\%)\end{array}$ & \begin{tabular}{|c|} 
Yield \\
Strength \\
(Mpa)
\end{tabular} & $\begin{array}{c}\text { Young } \\
\text { Modulus } \\
\text { (GPa) }\end{array}$ \\
\hline Untreated & 402.45 & 69.8 & $23.16 / 15$ & 56.24 & 220.03 & 207.88 \\
\hline Annealed & 389.34 & 62.15 & 25.22 & 64.12 & 212.54 & 302.32 \\
\hline Normalised & 452.13 & 120.36 & 22.7 & 63.23 & 242.26 & 288.12 \\
\hline Hardened & 734.32 & 293.4 & 6.9 & 37.39 & 278.11 & 632.47 \\
\hline Tempered & 421.76 & 100.01 & 23.2 & 69.01 & 232.78 & 293.63 \\
\hline
\end{tabular}

Table 3: Mechanical properties of heat treated and untreated ASTM A -36 steel. 


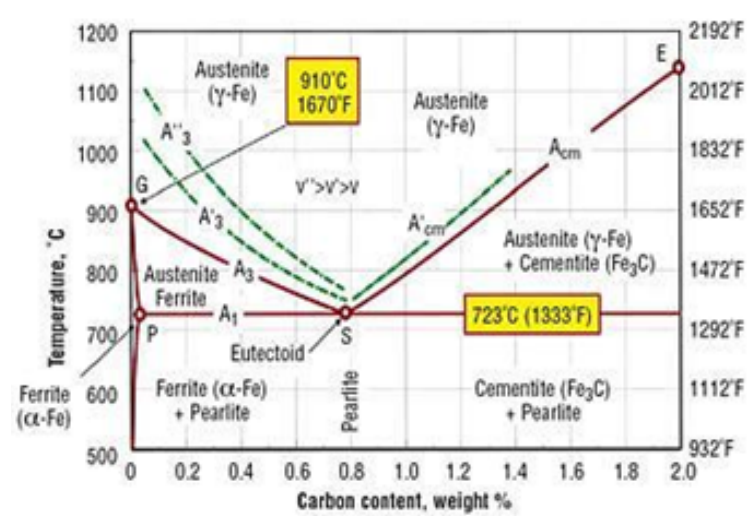

Figure 1: The Iron-Iron carbide phase diagram.

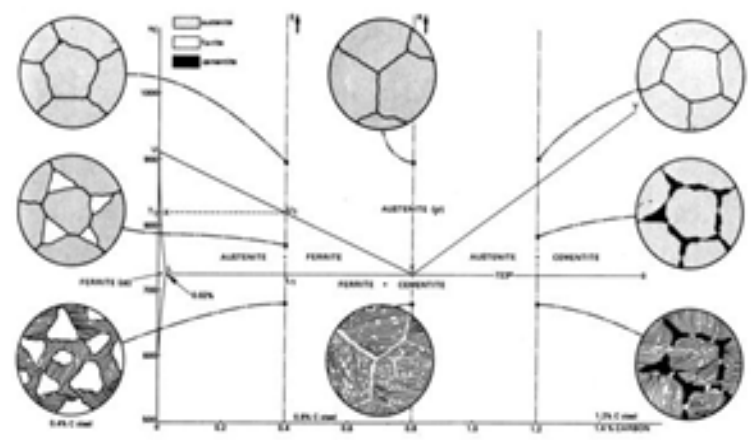

Figure 2: Grain size of microstructure at various phases.

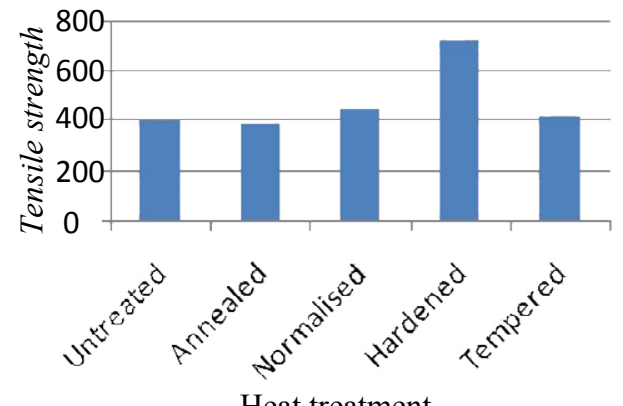

Heat treatment

Figure 3: Tensile strength of treated and untreated samples of ASTM A-36 steel.

specimens, except for the hardened specimen, there were tremendous increase in the toughness of the material which indicates that hardened material, though have a very high tensile stress, but at the expense of its toughness, hence where toughness is a major concern. However if strength is also desired along with hardness, this should not be done. It is seen that annealing causes a tremendous increase in \% elongation (ductility). It can be clearly seen comparing all the heat treatment processes, optimum Combination of Ultimate Tensile Strength, Yield Strength, \% elongation as well as hardness can be obtained through austempering only.

\section{Effect of heat treatment on microstructure}

The microstructure of untreated specimen (Figure 6) has two major constituents, which are ferrite (white) and pearlite (black). The light coloured region of the microstructure is the ferrite and the dark region is the pearlite. The microstructure of the annealed sample is shown in Figure 7. As it can be seen in Figure 7, the ferrite grains had undergone complete recrystallization and these constituted the major portion of the microstructure the annealed low carbon steel with stress free matrix. At $910^{\circ} \mathrm{C}$ the deformed structure was fully homogenized and during the slow cooling from austenizing range to room temperature the final microstructure consisted of fine ferrite grains in which the pearlite was more uniformly distributed.

Figure 8 shows the microstructure of the normalized ASTM-A36 mild steel. The normalized sample showed that the shape and size of the original austenite grains were influenced to a remarkable extent. The sample revealed a pearlite matrix in which shorter graphite flakes

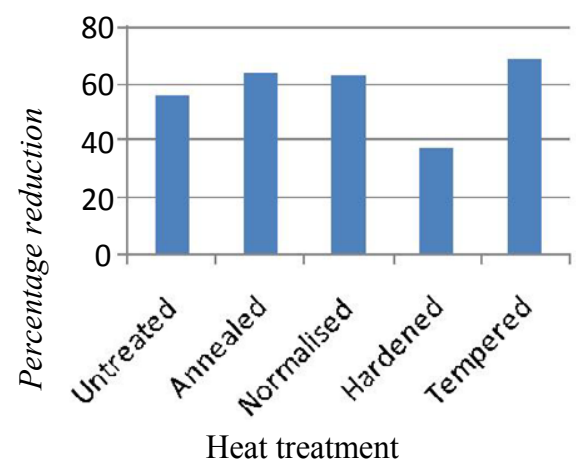

Figure 4: Percentage reduction of treated and untreated samples of ASTM A-36 steel.

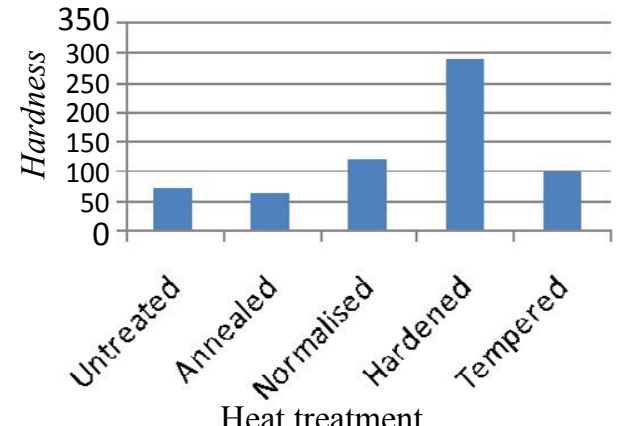

Figure 5: Hardness of treated and untreated samples of ASTM A-36 steel.

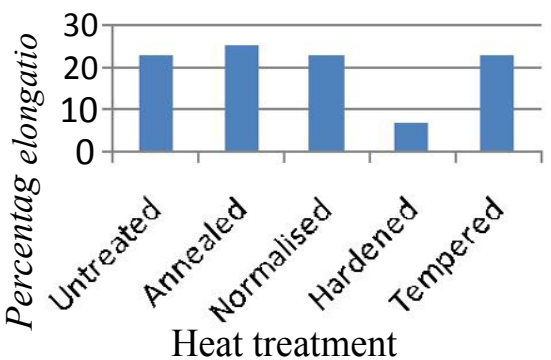

Figure 6: Percentage elongation of treated and untreated samples of ASTM A-36steel. 


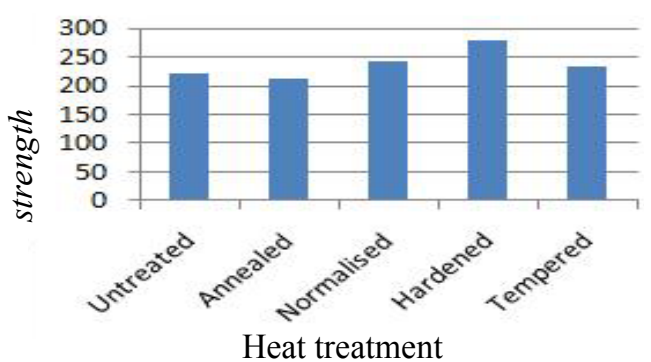

Figure 7: Yield Strength of treated and untreated samples of ASTM A-36 steel.

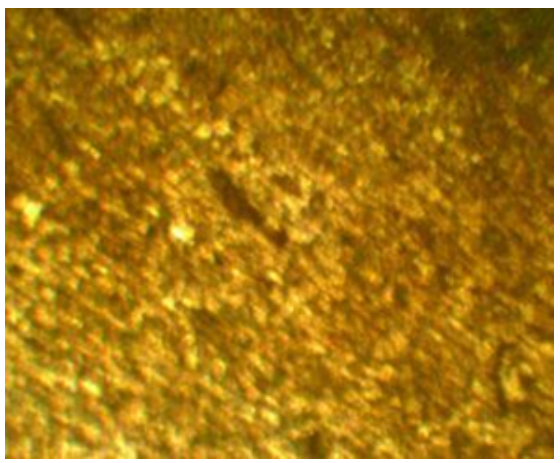

Figure 8: Microstructure of untreated ASTM A-36 steel (X400).

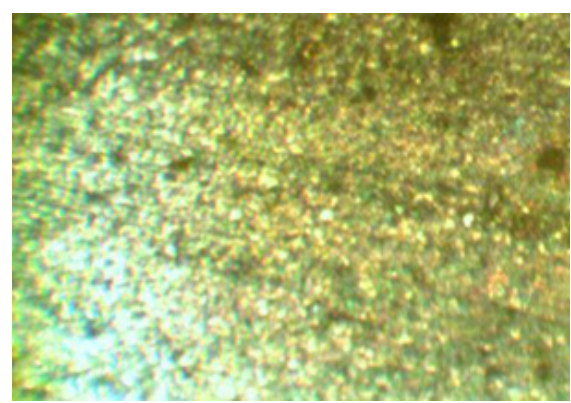

Figure 9: Microstructure of annealed ASTM A-36 steel (X400).

than in annealed sample existed. It was observed that there was many short graphite flakes surrounded with patches of uniformly distributed pearlite grains as seen in Figure 8.

Figure 9 shows the massive martensite structure of hardened sample, when medium carbon steels are rapidly quenched from its austenite temperature to room temperature, the austenite will decompose into a mixture of some medium carbon martensite and fewer pearlite as a result of this microstructure which is hard, hence, there was increase in tensile strength, hardness and reduction in ductility of the material (Figure 10) [11].

The microstructure of hardened and tempered at $450^{\circ} \mathrm{C}$ is shown in Figures 11 and 12. A highly recrystallized ferrite grains (white dotted areas) with some secondary graphite site was observed. This micrograph revealed that the microstructure of tempered specimen consisted of a number of appreciable carbide particles precipitated out from the matrix, which indicated that the precipitate carbide particles decomposed by a process of solution in ferrite matrix [12]. The summary of the observed microstructure of treated and untreated ASTM-A36 steel is given in Table 4.

In the microstructures of these specimens we have indicated the carbon-saturated region with arrow marks (Figures 7 and 8) and these help to find out the differences among the microstructures of untreated, annealed, normalized hardened and tempered specimens comparatively. As slow cooling is done in annealing so it transforms austenite to soft pearlite and also mixed with ferrite or cementite and this cementite increases the brittleness of the steel. Normalizing converts soft steel to moderate hard steel. In this case cooling rate is faster than annealing and for this reason, when the specimen is cooled in room temperature then ferrite and cementite are formed but their quantity is less. So the specimen is enhanced with considerable ductility by reducing its brittleness. In hardening process austenite structure is directly formed into martensite structure for fast cooling. Actually the rapid cooling converts most of the austenite into martensite which

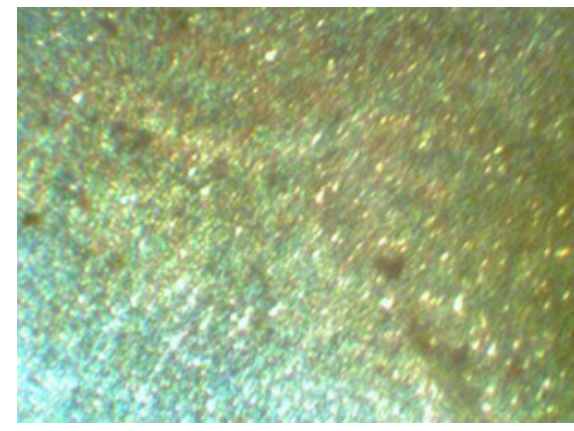

Figure 10: Microstructure of normalised ASTM A-36 steel (X400).

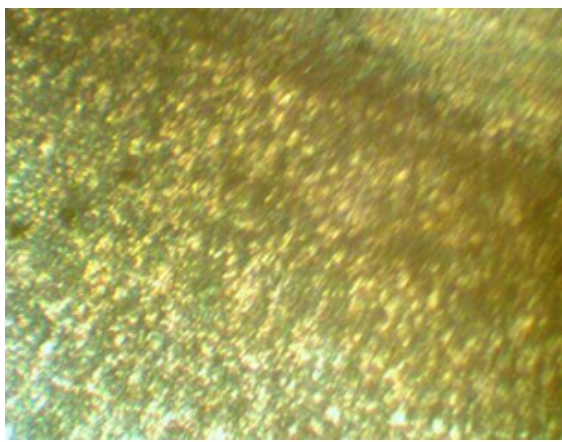

Figure 11: Microstructure of hardened ASTM A-36 steel (X400).

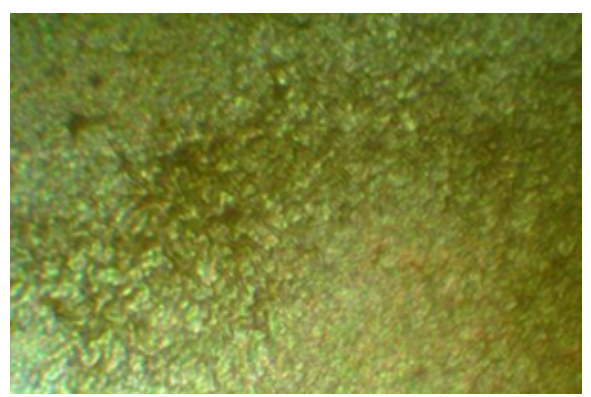

Figure 12: Microstructure of tempered ASTM A-36 steel (X400). 


\begin{tabular}{|c|c|}
\hline Heat treatments & Microstructure Developed \\
\hline Untreated & Graphite Flakes in ferrite and pearlite matrix \\
\hline Annealed & Graphite flakes in ferrite matrix \\
\hline Normalizing & Graphite flakes in pearlite matrix \\
\hline Hardened & Graphite flakes in martensite matrix \\
\hline Tempered & $\begin{array}{c}\text { Graphite flakes in martensite matrix } \\
\text { with recrystallized ferrite grains }\end{array}$ \\
\hline
\end{tabular}

Table 4: Summary of microstructure of treated and untreated ASTM A-36 steel.

is a hard constituent and more stable than austenite at ordinary temperatures. In tempering process austenite structure is directly formed into martensite structure matrix with recrystallized ferrite grains.

\section{Conclusions}

From the results obtained, it can be said that mechanical properties depends largely upon the various form of heat treatment operations and cooling rate. Hence depending upon the properties and the applications that may be required for any design purpose, a suitable form of heat treatment should be adopted. For high ductile and minimum toughness, annealed mild steel will give satisfactory results. According to the results of investigation on the effect of heat treatment on mechanical properties and microstructure of ASTM-A36 mild steel, the following conclusions were made: Tensile strength, yield strength and hardness of low carbon ASTM A-36 steel increased with plastic deformation while ductility and impact strength decreased due to strain hardening effect. Normalization treatment had also resulted in higher tensile strength and hardness than annealed samples. This treatment is recommended as final treatment after manufacturing. The tempered samples gave an increase in tensile strength and hardness than untreated sample as a result of formation of tempered martensite and resultant ferrite structure that were obtained. Hardened sample had the highest tensile strength and hardness with lowest ductility and impact strength when compared to other heat treated samples. Hardening is strongly recommended when the strength and hardness are the prime desired properties in design. The mechanical properties of ASTM A-36 steel can be altered through various heat treatments. The results obtained confirmed that improvement in mechanical properties that can be obtained by subjecting ASTM A-36 steel to different heat treatments investigated in this study.

\section{References}

1. Dell KA (1989) Metallurgy Theory and Practical Textbook. American Technica Society, Chicago.

2. John VB (1980) Introduction to Engineering Materials. (2 $\left.{ }^{\text {nd }} E d\right)$, Macmillan Publishing Company Ltd.

3. Alawode AJ (2002) Effects of Cold Work and Stress Relief Annealing Cycle on the Mechanical Properties and Residual Stresses of Cold-Drawn Mild Steel Rod. Mechanical Engineering Department, University of Ilorin, Nigeria.

4. Funatani K, Totten GE (1997) Present Accomplishments and Future Challenges of Quenching Technology. Proceedings of the 6th International Federation of Heat treatment and Surface Engineering Congress, IFHTSE, Kyongju, Korea.

5. Nam WJ, Bae CM (1999) Coarsening Behavior of Cementite Particles at a Subcritical temperature in a medium Carbon Steel. Scripta Materialia 41: 313318

6. Manchanda VK, Narang GBS (2005) Materials and Metallurgy. (6 th $^{\text {th }}$ d), Khanna Publishers.

7. ASTM E18 (2008) Standard Test Method for Rockwell Hardness of Metallic Materials. American Society of Testing and Materials.

8. ASTM E23 (2008) Standard Test Method for Notched Bar Impact Testing of Metallic Materials. American Society of Testing and Materials.

9. ASTM E8 (2008) Standard Test Method for Tension Testing of Metallic Materials. American Society of Testing and Materials.

10. Jokhio MH (1991) Effect of Retained Austenite on Abrasive Wear Resistance of Carburised SAE $8822 \mathrm{H}$ Steel. Mehran University of Engineering and Technology, Jamshoro.

11. Hu HJ, Zhai ZY, Li YY, Gong XB, Wang H, et al. (2015) The simulation researches on hot extrusion of super-fined tube made of magnesium alloys. Russian Journal of Non-Ferrous Metals 56: 196-205.

12. Gong X, Li H, Kang SB, Cho JH, Li S (2010) Microstructure and Mechanica Properties of Twin-roll Cast Mg-4.5Al-1.0Zn Alloy Sheets Processed by Differential Speed Rolling. Materials and Design 31: 1581-1587. 